Abstracta Iranica Abstracta Iranica

Revue bibliographique pour le domaine irano-aryen

Volume 30 | 2010

Comptes rendus des publications de 2007

\title{
« Picturing Persian Victory: The Painted Battle Scene on the Munich Wood ». Ancient Civilizations from Scythia to Siberia, 13, 2007, pp. 3-30 avec de nombreuses illustrations en couleur.
}

\section{Astrid Nunn}

\section{OpenEdition}

\section{Journals}

Édition électronique

URL : http://journals.openedition.org/abstractairanica/37695

DOI : 10.4000/abstractairanica.37695

ISSN : 1961-960X

Éditeur :

CNRS (UMR 7528 Mondes iraniens et indiens), Éditions de l'IFRI

Édition imprimée

Date de publication : 8 avril 2010

ISSN : 0240-8910

\section{Référence électronique}

Astrid Nunn, « «Picturing Persian Victory: The Painted Battle Scene on the Munich Wood ». Ancient Civilizations from Scythia to Siberia, 13, 2007, pp. 3-30 avec de nombreuses illustrations en couleur. », Abstracta Iranica [En ligne], Volume 30 | 2010, document 95, mis en ligne le 08 avril 2010, consulté le 26 septembre 2020. URL : http://journals.openedition.org/abstractairanica/37695; DOI : https:// doi.org/10.4000/abstractairanica.37695

Ce document a été généré automatiquement le 26 septembre 2020.

Tous droits réservés 


\title{
« Picturing Persian Victory: The Painted Battle Scene on the Munich Wood ». Ancient Civilizations from Scythia to Siberia, 13, 2007, pp. 3-30 avec de nombreuses illustrations en couleur.
}

\author{
Astrid Nunn
}

1 En 1970 arrivaient en Allemagne par le marché des poutres peintes qui furent prises en charge par la "Archäologische Staatssammlung » de Munich. C'est un énorme mérite de l'A. de les avoir redécouvertes, étudiées, liées à d'autres poutres peintes conservées dans les réserves du Musée d'Afyon et replacées dans leur contexte original. Les poutres du Musée d'Afyon proviennent d'une tombe située près de Tatarlı à $30 \mathrm{~km}$ au nord-est de la sous-municipalité de Dinar, elle-même située dans la préfecture d'Afyon, à la limite entre l'antique Lycie et Phrygie. Elle fut pillée en 1969, à la suite de quoi le Musée d'Afyon organisa une fouille de secours de quelques jours. L'ensemble des poutres formait une chambre funéraire enfouie sous un tumulus de terre, comme le sont les tumuli phrygiens. Le tumulus mesurait environ $6 \mathrm{~m}$ de hauteur et $50 \mathrm{~m}$ de diamètre, la chambre funéraire était longue de $2,50 \mathrm{~m}$, large de $2 \mathrm{~m}$ et haute de $1,85 \mathrm{~m}$. Grâce à l'analyse dendrochronologique de P. Kuniholm, il a pu être prouvé que les poutres de Munich et d'Afyon provenaient de deux arbres, un cèdre et un genévrier, très vraisemblablement abattus en 478 av. J.-C. $+4 /-7$.

Il s'est avéré que les poutres qui avaient été amenées à Munich proviennent du mur est. Sur la frise supérieure se trouve une scène de procession avec 20 personnes, 16 chevaux et deux chars. Des convois similaires sont connus par des stèles funéraires et des peintures de Karaburun. En dessous et sur une poutre longue de 2,21 m, on voit une bataille entre Perses et Scythes, de laquelle, bien évidemment, les Perses sortent 
vainqueurs. Les poutres du mur nord, aujourd'hui à Afyon, comportent des fauves disposés de manière antithétique, des cavaliers en armes, un cortège de chars et une scène de chasse (?) où figurent des taureaux ailés avec une panthère et des oiseaux. Les programmes des murs ouest et sud sont beaucoup plus difficiles à reconstituer. Même si aujourd'hui les couleurs sont relativement effacées, on en devine parfaitement l'éclat de jadis.

3 La redécouverte de la chambre funéraire de Tatarlı est une chance extraordinaire pour la science. Nous disposons dorénavant de $12 \mathrm{~m}^{2}$ de peinture achéménide sur bois.

$4 \quad$ [Ce compte rendu concerne également le $\mathrm{n}^{\circ}$ 94]

INDEX

Thèmes : 3.2.2. Pré-Achéménides et Achéménides

\section{AUTEURS}

\section{ASTRID NUNN}

Université de Munich 